\title{
Using communities of practice towards the next level of knowledge-management maturity
}

Authors:
Lameshnee Chetty ${ }^{1}$
Martie Mearns ${ }^{1}$
Affiliations:
${ }^{1}$ Centre for Information and
Knowledge Management,
University of Johannesburg,
South Africa
Correspondence to:
Martie Mearns
Email:
mearnsm@uj.ac.za
Postal address:
PO Box 524, Auckland Park
2006, South Africa
Dates:
Received: 04 Oct. 2011
Accepted: 10 May 2012
Published: 23 July 2012
How to cite this article:
Chetty, L. \& Mearns, M.,
2012, 'Using communities
of practice towards the
next level of knowledge
management maturity',
SA Journal of Information
Management 14(1), Art.
\#503, 9 pages. http://dx.doi.
org/10.4102/sajim.v14i1.503

(C) 2012. The Authors. Licensee: AOSIS OpenJournals. This work is licensed under the Creative Commons Attribution License.
Background: Effective communities of practice undoubtedly impact organisations' knowledge management and contribute towards building a learning-organisation culture. Communities of practice represent an environment conducive to learning and for exchanging ideas, and they are a formal learning forum. However, the level of organisational learning to which communities of practice contribute is difficult to measure.

Objectives: The research was conducted to analyse the impact of communities of practice on building a learning organisation. The organisational system, culture and people offer the key towards leveraging knowledge as a strategic resource in a learning organisation. The awareness of the organisation concerning knowledge management was measured on a replicated knowledge-management maturity model.

Method: The organisational knowledge base was analysed prior to the implementation of the communities of practice and was compared to the situation three years later. The research was based on experiential learning cycles that consisted of five consequential but perpetual stages, namely reflect, plan, act, observe and reflect again.

Results: The results indicated that communities of practice were instrumental in leveraging the organisation to the next level in the knowledge-management maturity model. A collaboration framework was developed for each business unit to work towards a common goal by harnessing the knowledge that was shared.

Conclusion: Although a positive impact by communities of practice is visible, an instrument for the measurement of intellectual capital is necessary. It is recommended that the monetary value of knowledge as an asset is determined so that the value of the potential intellectual capital can be measured.

\section{Introduction}

Communities of practice $(\mathrm{CoP})$ have become an imperative element in accumulating and maintaining an organisation's intellectual capital (IC) (Davel \& Snyman 2005). Companies that adopt a strategic approach instead of an opportunistic approach to managing their IC have harnessed opportunities to improve their market position (Klein 1998:4, Kruger \& Johnson 2011:269). Despite realising the importance of knowledge management, understanding how to manage knowledge is still not an easy task for many organisations (Arling \& Chun 2011:231).

CoPs are strategic knowledge-management tool utilised in an effort to capture and share tacit knowledge (Wenger 2007). In essence, CoPs are proving to be a breakthrough for organisations to identify and manage their tacit intellectual assets so that these can become explicit sources to be utilised as IC. If CoPs are nurtured by management structures within organisations, they may be able to generate knowledge as one of their greatest assets (Pearlson \& Saunders 2006:287). The sharing of information, thoughts and ideas based on a common goal in a CoP results in members of the community gaining more knowledge and raising each other's competence through sharing (Burke 2000:18). The advantage of a CoP is that members of that community in an organisation are peers and are alike for that reason, regardless of job titles and positions. This equality is the result of the relationship on which a $\mathrm{CoP}$ is based. Employees are therefore able to naturally share knowledge without trepidation or evaluation from other employees. Valuing the expertise and the sharing of knowledge is seen as one of the characteristics of a knowledge-based organisation. Where knowledge creation is at the centre of an organisation, the bridge between working and innovation is learning.

A learning organisation is an organisation that learns vigorously and collectively, continually transforming itself to more effectively manage knowledge and empower its people to learn (Gilley \& Maycunich 2000:14). Learning organisations are continually expanding their capacity 
to create their own future (Aktarsha \& Anisa 2011:27, Senge 1990:3). Such organisations are skilled at creating, acquiring and transferring knowledge and at modifying the organisation's behaviour to reflect new knowledge and insight (Garvin 1993:79, Smith 2011:7). Typical activities in a learning organisation are systematic problem solving, experimentation with new approaches, learning from own and others' experiences and transferring knowledge efficiently. The steps that are required to become a learning organisation include, firstly, the creation of an environment that is conducive to learning. Secondly, the exchange of ideas should be stimulated, and thirdly, learning forums should be created (Garvin 1993:91; Wilson 2011:111).

MultiChoice is an example of a learning organisation that favours the use of CoPs as a learning forum to exchange ideas and create a learning environment to ultimately capture and utilise intellectual assets. Using MultiChoice as a case in point, this article argues that CoPs can make a substantial contribution towards creating a learningorganisation culture. This argument is moulded around the main research problem that was investigated, namely: What contribution does CoPs make towards building a learning organisation such as MultiChoice. In order to measure whether MultiChoice has become a learning organisation, it is important to determine MultiChoice's level on the knowledge-management maturity model (Snyman \& Kruger 2005:10). This will gauge the organisation's progress towards being in a position to identify IC as a true business asset.

IC is considered to be one of the main drivers of knowledge management. The objective of organisations should be to maximise IC by linking it to knowledge management. Zhou \& Fink (2003:36) state that this objective can only be realised if knowledge processes are managed methodically and with intent. This article highlights the way in which MultiChoice has used a knowledge-management tool such as CoP in order to build more effective processes and capture tacit knowledge to ultimately derive organisational IC.

\section{Defining the case study}

MultiChoice was founded in 1986 as a subscription television service in South Africa and has as its mission the distribution of digital media entertainment, content and services to subscribers through multiple devices (MultiChoice 2010). MultiChoice is a knowledge-intensive company that, in 2006, has formally embraced knowledge management. The research for this article was conducted as a longitudinal study drawing on the findings of a 2006 baseline report (Hiscock 2006).

The position of knowledge management in MultiChoice prior to the introduction of CoP had been analysed in the 2006 baseline report conducted as a knowledge audit (Hiscock 2006). Key stakeholders were identified throughout the organisation. A combination of one-on-one interviews and focus groups were completed to identify the knowledge entities that existed within the organisation, the knowledge flows between the entities and the resulting knowledge gaps that could then be identified. To ensure a good cross section of all levels throughout the organisation, 55 oneon-one interviews were conducted, and 139 participants were included in the focus-group discussions. The purpose of the baseline assessment was to determine the level of organisational learning in MultiChoice in an attempt to understand the (then) current knowledge-management processes of the organisation. It was furthermore necessary to identify and understand the key drivers of business value and to identify the areas of improvement and strategic gaps.

As a result of the baseline assessment, it was concluded that there is an indication of an awareness of knowledge management as an emerging business discipline. The awareness of the capability of knowledge management to improve MultiChoice's performance, however, remained low. Despite this low awareness, the overall interest in knowledge management was high. This was supported by the enthusiasm shown by interviewees in the baseline report requesting to be kept informed of follow-up knowledgemanagement activities.

The baseline assessment also highlighted and supported the fact that MultiChoice is familiar with many knowledgemanagement principles. In addition these knowledgemanagement principles are actively practiced. These include the need to focus on the consistent application and improved quality of knowledge-management principles across the company. This meant that MultiChoice had to establish a rigorous knowledge-management awareness campaign within the organisation.

The knowledge-management pyramid of excellence (Figure 1) was adopted as the agreed framework for knowledgemanagement implementation at MultiChoice. The framework represents a systematic approach to implementing and adopting six core knowledge-management principles.

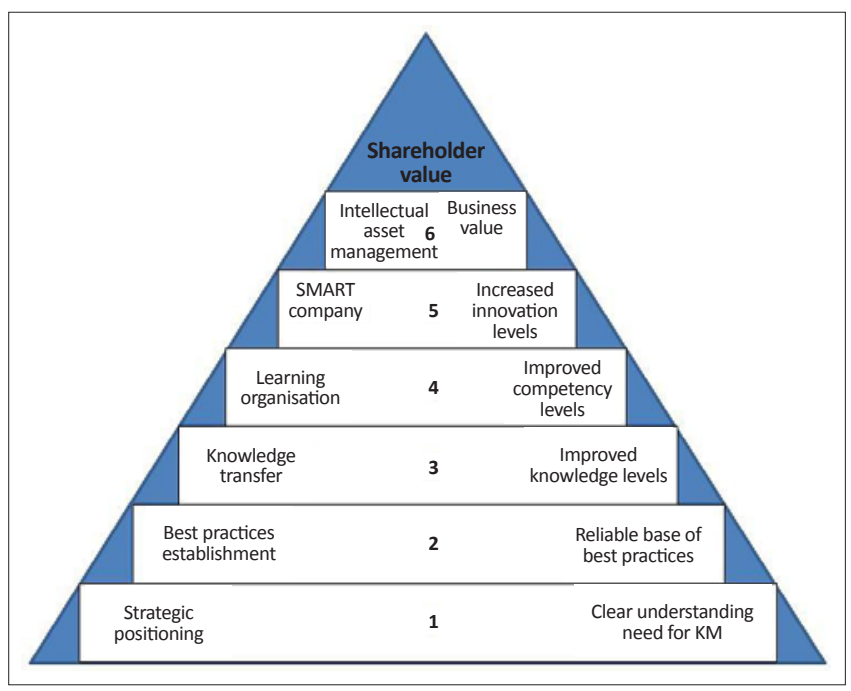

Source: Adapted from Hiscock, M., 2006, 'Knowledge management baseline assessment', Unpublished internal report for Multichoice.

FIGURE 1: Pyramid of Excellence Framework and Maturity Model. 
The six core knowledge management principles are strategic positioning, the establishment of best practices, knowledge transfer, learning organisation, becoming a specific measurable attainable realistic timely (SMART) company and intellectual-asset management. These have been combined with the knowledge-management maturity model that is discussed later and shown in Figure 4, Figure 5 and Figure 6. Considering the baseline report, the third level, namely knowledge transfer, showed that informal CoPs do exist, but they could be further optimised to focus on specific knowledge areas. It was also found that more CoPs could be developed.

An analysis of the critical success factors of CoPs in MultiChoice was conducted by Murphy (2008). Based on the baseline study of Hiscock (2006) and building on the work of Murphy (2008), a period of time had to elapse to assess the level of organisational learning that the formalised CoPs contributed. This article therefore reports on the results of the investigation into the current level of organisational learning that CoPs contribute to MultiChoice.

\section{Research methods}

In order to grasp the extent to which CoPs have impacted on MultiChoice, the methodology had to interpret factual reflections and opinions of the community members and organisation. The research methodology used for this study is primarily based on Participatory Action Research (PAR). PAR is a method of research where creating an optimistic social change is the principal driving force. Hughes and Seymour-Rolls (2000) contend that:

PAR grew out of social and educational research [that] exists today as one of the few research methods which embrace principles of participation ... reflection ... empowerment and emancipation of groups seeking to improve their social situation. (p. 1)

The possibilities of using PAR in the information and knowledge-management sciences are vast and entirely appropriate. Firstly, a PAR project arises from the practitioners themselves, the practitioners being the participants who are chosen as the sample. The participants become the basis of the actionable change, and their qualitative feedback becomes the basis for the scientific research outcomes. Secondly, PAR is research focussing on developing new knowledge and theory (Hughes \& SeymourRolls 2000, Genat 2009:102). Similarly CoPs are platforms used as change enablers whilst continuously gaining new knowledge by experiencing in practice or in action; this is not unlike the action-learning groups which are utilised for PAR. CoPs are therefore actually continuous, cyclic PAR projects. The research design is based on Kolb's Experiential Learning Cycle (Kolb \& Yeganeh 2011:4), which applies the approach of participatory action research in the following stages:

- Reflect 1: The participants are engaged in a critical evaluation process regarding what is currently happening in the process that needs to be changed. The increased understanding which emerges from this first session of initial criticism is put to use in creating the later stages.
- Plan: Subsequent to the feedback that has emerged in the initial reflection stage, planning sessions then occur. The action points are distributed and allocated to participants.

- Act: This phase is putting the plan into action. This is where the changes are implemented as stipulated in the reflection and planning phase.

- Observe: Observations are made by the participants on the impact of their implementation plan. Observations are based on whether prior assumptions were correct, whether the team is working together and what impact the implementation has had on other people in the organisation.

- Reflect 2: This is the second reflection phase of the initial cycle. In this phase, observations are brought forward and discussed with all participants, and a new plan is suggested based on the new critics.

Focus groups (consisting of 10 members each) were applied to document the stages of the experiential learning cycle in the PAR approach. A purposive sample of two CoPs was drawn from a possible five CoPs, and these acted as the focus groups for the PAR sessions that were documented. The two CoPs that participated in the research were the project management (PM) CoP and the knowledge management (KM) CoP. The criteria were included as part of the sample stipulated that the CoPs should meet at least once in two months. The subject matter experts of the CoPs and the objective of the CoPs should be representative of each other, and the CoPs should consist of more than five people.

In addition to focus groups, a survey was also utilised to capture relevant information from an organisational perspective. Each of the 11 business divisions within MultiChoice has a knowledge champion, and each of the 11 knowledge champions was included in the survey. Questionnaires were administered to the 11 knowledgemanagement champions, which resulted in a $90.9 \%$ response rate. The survey aimed to achieve a holistic organisational view of the role of CoPs in MultiChoice. The total sample size for the data collection stage of this study was therefore 31 participants, two CoPs with 10 participants each and 11 knowledge champions.

\section{Positioning knowledge management, intellectual capital and Communities of practice}

In essence, knowledge management can be defined as a dynamic, multi-disciplined approach towards achieving organisational objectives by making the best, most efficient use of knowledge. Earl (2001:218) has identified three knowledgemanagement schools of thought: technocratic, economic and behavioural. The technocratic approach emphasises technology-based information-management applications, such as knowledge bases and organisational directories disclosing the repositories and custodians of knowledge. The economic approach focuses on the exploitation of knowledge as an asset. The behavioural approach, to which MultiChoice subscribes, focuses on business strategy and culture by 
facilitating knowledge exchange through communities and awareness (Earl 2001:218).

The technocratic approach is however not ignored at MultiChoice, but technology for knowledge sharing is seen from a supportive perspective whilst the economic slant of knowledge sharing is regarded as an outcome once knowledge maturity is reached. There is therefore a focus on the organisational system, culture and people as supported by Carrillo (2004), Currie and Kerrin (2004) and Hwang (2005). The people, culture and relationship of the organisation are therefore key to IC.

Intellectual capital consists of human capital, which encapsulates the knowledge and wisdom within the employees of an organisation; the structural capital that refers to the hardware, software and trademarks left behind in an organisation once the employees have vacated; and the relational capital referring to the relationships built up with the customers and stakeholders. IC is often inadequately identified and assessed because information is salvaged in a dissimilar fashion, and fiscal reporting patterns are frequently unsuccessful in recognising IC as an asset (Industry Canada 1999). Bontis (1998:65) views human capital as a source of innovation and strategic renewal, saying that the essence of human capital lies in the sheer intelligence and ingenuity of staff members. Using more of what people know requires minimising mindless tasks and bureaucracy. For Stevenson (1995), command and control theories of management are inappropriate if human capital is to be unleashed. Opportunities should be created for making private knowledge public and tacit knowledge explicit (Jeon, Kim \& Koh 2011:12423). Informal as well as virtual networks, relationships, forums and CoPs are all important in harnessing what people know and leveraging it in an organisation. It can therefore be concluded that a CoP is a knowledge-management tool that can be utilised to harness IC that exists within an organisation's human capacity.

There have been various Intellectual Capital frameworks that have been developed by pioneers in the field, such as Sveiby's Model (1997), Sullivan's model (2000) and the Skandia Intellectual Capital Value Scheme developed by Edvinson (2002). The MultiChoice Intellectual Capital framework takes into account a number of factors from the abovementioned three models and is shown in Figure 2.

Taking the above framework into account, at MultiChoice, IC is captured using CoPs that reside on the Innovation and Knowledge Management levels.

According to Sandrock (2008:78), a community of practice has three dimensions:

1. the domain, which is the topic of interest on which the group wishes to collaborate

2. the members, the people that make up the community of practice where they trust each other's input and are willing to share and investigate new ideas and methodologies

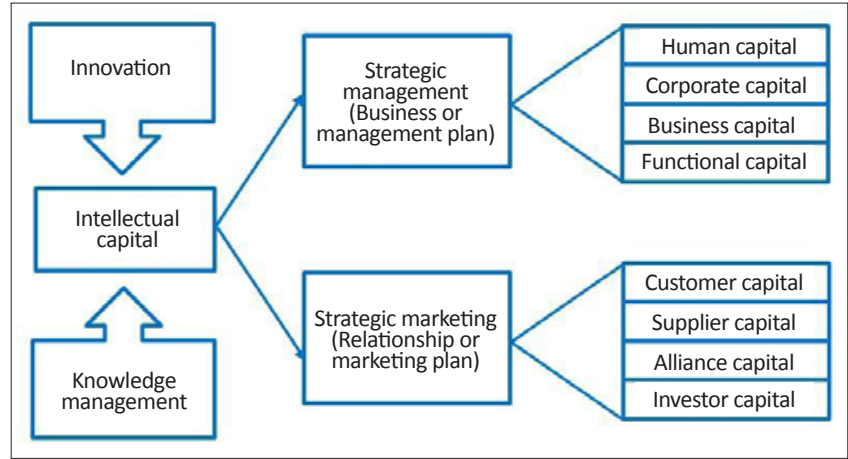

Source: Authors' own data

FIGURE 2: MultiChoice's Intellectual Capital Framework.

3. the community work, where the sharing of best practices takes place, and members share experiences and are able to fulfil the objective of the community of practice.

It is important to note that the most important role within the above-mentioned dimensions is the responsibility of the CoP coordinator. This person works hand in hand with the CoP leader but has the additional task of making sure that the community meets on a regular basis, is constantly updated, the online community portal is up to date and relevant information and collaboration takes place in a structured and healthy manner.

Nickols (2003:4) specifies that there are two types of CoP, sponsored and self-organising. Both types of CoP are alike in their relations but are different in the way in which they are formed. Sponsored CoPs are initiated and planned by management, often a Chief Knowledge Officer. Once the $\mathrm{CoP}$ is aware of and participates in the knowledge sharing community, this type of CoP will develop into a selforganising CoP. Self-organising CoPs pursue the shared interests of the group members whilst being self-governed (Jeon, Kim \& Koh 2011:12423). They are formed informally in an organisation by a group of colleagues who might share the same interest on a topic, industry or subject matter. This type of $\mathrm{CoP}$ adds value to an organisation by sharing lessons learnt, best practices and problem solving; in essence, they learn from one another. The two CoPs studied for this research are both sponsored CoPs, sponsored by MultiChoice's management.

Figure 3 demonstrates the cycle of learning that takes place amongst members of a CoP. Knowledge capital is created and utilised in an effort to perfect processes and skills. Knowledge capital is generated by documenting knowledge and validating the knowledge against employees' experiences and expertise, thus resulting in a continuous cycle of learning and adapting. Barab and Duffy (1998) call this cycle of continuous learning 'practice fields'. Knowledge capital is applied to problem solving, quality assurance and the leveraging of knowledge amongst employees. This knowledge capital is then taken back to working groups and teams to which each employee belongs in the organisation; then it is applied. 
A direct link exists between learning in an organisation and innovation. The knowledge-management maturity model, according to Snyman and Kruger (2005:10), serves as a methodology through which one can decipher how far an organisation has evolved towards becoming a learning organisation. Gallagher and Hazlett (2000) state that maturity models are typically:

incremental in nature and represent an attempt to interpret a succession of positions, phases or stages with regard to growth and maturity, all with the ultimate aim of improving processes and business performance. (p. 12)

This means that, in order for knowledge to be effectively managed towards a higher level of maturity, organisations must grow to such an extent that these organisations are capable of leveraging knowledge as a strategic resource. In addition, the use of knowledge management should be applied in a productive way and in doing so enhance the development of organisational competence and capabilities. Figure 4 demonstrates Snyman and Kruger's (2005:10) strategic knowledge-management maturity model.

The four-stage process depicted in Figure 4 includes initiate, be aware, manage and optimise. This reflects the dedication of knowledge management in identifying and relating knowledge-management issues to organisational growth and profitability. Klimko (2001:269) refers to maturity modelling as a developing process that depicts the growth of an entity over a period of time. This includes explicitly defining, managing, measuring and controlling the growth of an entity. The MultiChoice knowledge-management maturity model replicates Snyman and Kruger's (2005:10) maturity model in Figure 5.

When knowledge is not managed, it does not have the desired impact on the business. However, if business strategies reflect learning, knowledge excellence would have been reached.

\section{Findings to plot the organisational learning maturity}

The two CoPs that participated in the PAR approach showed valuable outputs from the reflection stages. The findings that emanated from the experiential learning cycles for the project management CoP showed the value of reflection, planning, acting and observation that took place. The first finding during the first experiential learning cycle for the project management $\mathrm{CoP}$ indicated that participation in the CoP needs to be encouraged. The development of an incentive programme was planned and activated by establishing an incentive scheme three months later. Members observed that the incentive scheme promised high rewards. This needed to be proven in a credible approach as participants did notbelieve that such incentives existed. During the second experiential learning cycle for the project management $\mathrm{CoP}$, reflection on the first finding indicated that the usage of the CoP's virtual site and overall awareness of the project management CoP did not pick up after the incentive scheme was established. In order to deal with the credibility of the incentives, a plan

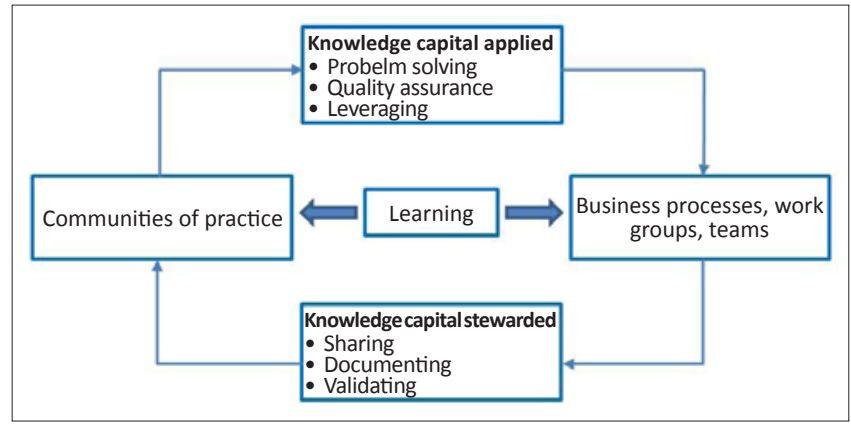

Source: Adated from Wenger, E., 2007, Communities of practise leaning as a social system, viewed 14 June 2010, from http://www.co.i.l.com/coil/knowledge-garden/cop/lss.shtml

FIGURE 3: Multi-membership learning cycle of CoPs.

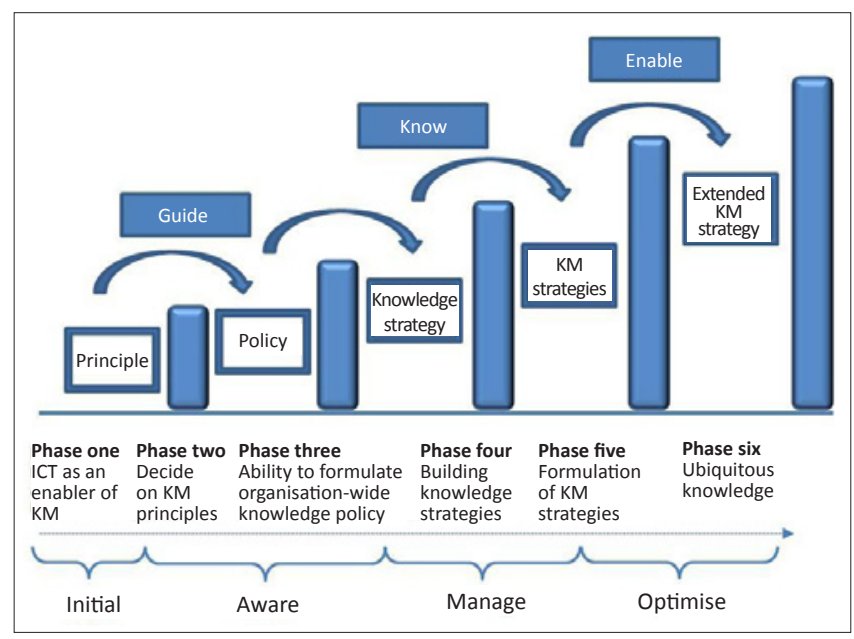

Source: Adapted from Snyman, M.M.M. \& Kruger, C.J., 2005, 'Formulation of a Strategic Knowledge Management Maturity Model', Journal of Knowledge Management 8(1), 5-10 http://dx.doi.org/10.1108/13673270410523871

FIGURE 4: Strategic knowledge management maturity model.

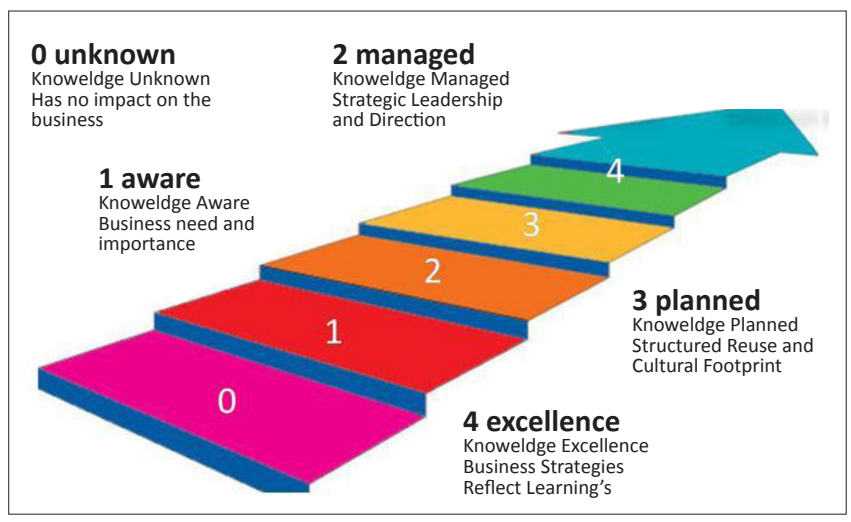

Source: Authors' own data

FIGURE 5: The MultiChoice Maturity Model.

was devised for using sponsors. Sponsors were responsible to present the CoP's strategic objectives and vision in alignment with the corporate strategy and to meet with the $\mathrm{CoP}$ to publicise the incentive. Further awareness campaigns were planned via MultiChoice's intranet. Controversy exists in the literature on the practice of incentives and reward systems for enhancing the quality of work. Some authors are of the opinion that incentives and rewards are counterproductive to establishing an organisational culture in which knowledge sharing is embedded (Gurteen 2010, Kohn 1999, 
Pink 2010). Incentives and rewards are therefore aspects that require further investigation in the field of knowledge management. However, Stafford and Mearns (2009) reported on individuals and teams responding positively to public recognition within an organisation for contributions made to knowledge-sharing initiatives and activities.

The second finding during the first experiential learning cycle for the project management $\mathrm{CoP}$ indicated that there were various project managers from different business units working in silos, and the project management CoP wanted to act as a platform for them to collaborate. There were existing meetings to target the same objective, namely for project managers to work in synergy rather than in silos. Even though meetings were already scheduled with the same purpose as that of the project management $\mathrm{CoP}$, the structure of the meetings did not follow a specific agenda and debates usually went around in circles. There was no facilitator that took responsibility for reaching any given objective. It was planned that the meetings would therefore be pulled in under the umbrella of the project management $\mathrm{CoP}$ in order to give it more structure and to achieve the expected outcomes. This reflection and plan still needs to be acted on for a second experiential learning cycle to commence.

The experiential learning cycle for the knowledge management $\mathrm{CoP}$ indicated that, in order to assist the organisation in learning and sharing best practices, in sharing expertise online and in encouraging innovation, a collaboration framework would have to be created. A collaboration framework (Figure 6) was planned along the same principles as Kolb's Experiential Learning Cycle. Each stage in the collaboration framework would have a different focus area. In the 'learning' stage, preparing the organisation via learning courses, e-library and virtual counselling would be the primary focal area.

The 'act' stage would enable people to work effectively and efficiently towards a common goal. Participation would be enabled over time and space using a virtual platform. The three primary elements in the action phase were identified as communication, workplace and co-ordination. Communication is seen as the method by which messages are conveyed over a platform, such as text, voice and video chat, online conferencing, web casts, blog forum, RSS, podcasts and e-mail. Workplace signifies the working area shared between individuals, such as collaborative editing, self-organising knowledge lists of project documents and collaboration areas. Coordination is the management of project tools, to-do calendars and workshops. The three elements mentioned, communication, workplace and coordination, can be further re-used.

The reflection stage of the envisioned collaboration framework is seen as the documentation, sharing and re-use of experiences to improve the way in which CoP members work. The reflection stage would probably be most beneficially achieved by getting feedback on best practices, constructive criticism and ways of working. All three stages, namely learning, action and reflection, would be underpinned and supported by social networking elements, such as making expertise available online and through

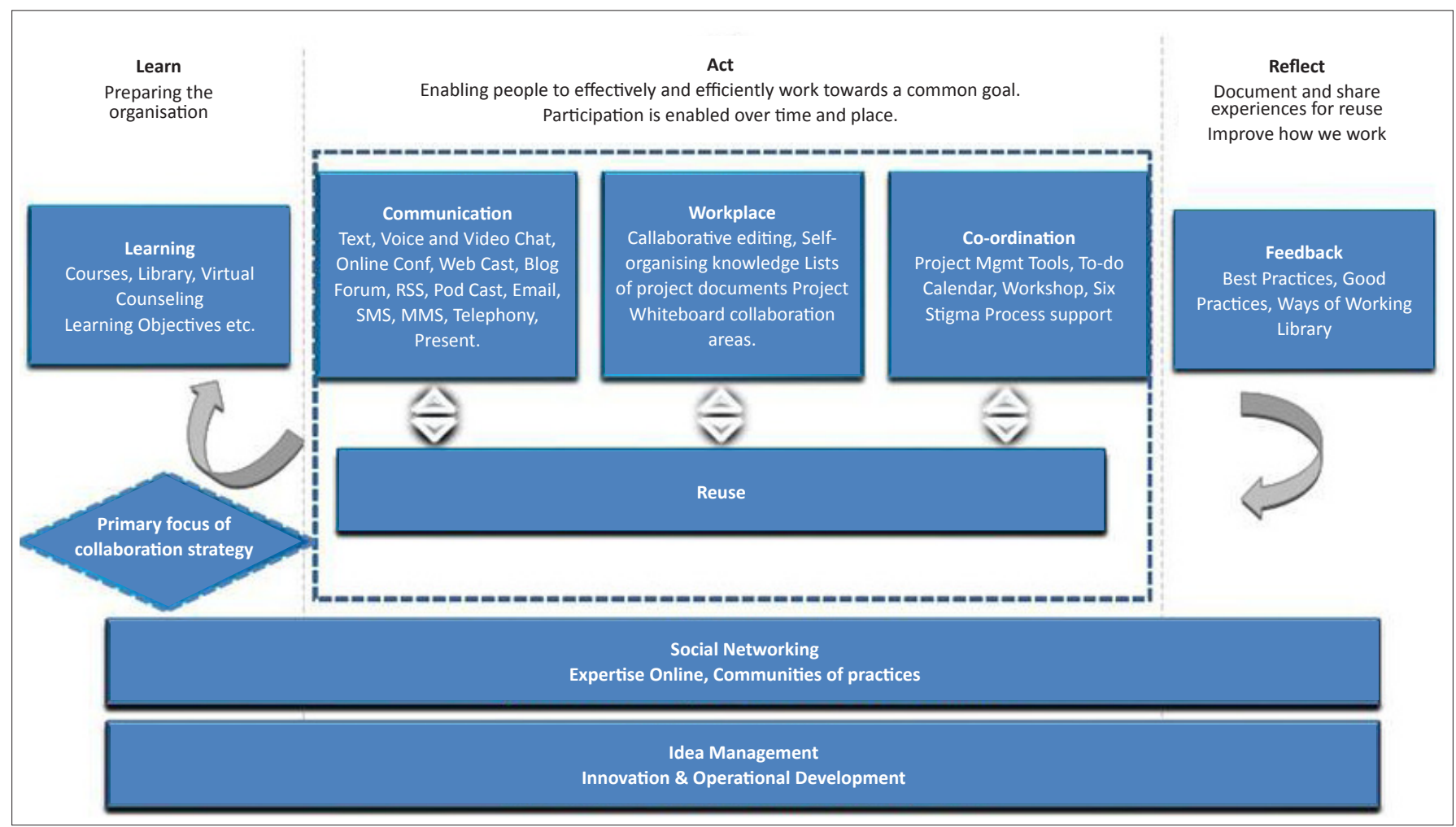

Source: Authors' own data

FIGURE 6: The MultiChoice Collaboration Framework. 
virtual CoPs. The three stages would be further supported by idea management, which is continuous innovation and operational development working towards operational excellence. The members were of the opinion that building the collaboration platform would be less demanding. However, there was a perception that the content management and collaboration aspects will be more tedious efforts.

Due to the comprehensive nature of the plan that was designed to assist the organisation to learn and share, an entire experiential learning cycle has not yet been completed. The collaboration framework was being acted on at the time of the writing of this article. The virtual collaboration platform was initiated by the knowledge management CoP, and plans to pilot the framework and test the applicability was underway. Lessons learnt from the pilot test will be taken into account for the organisation-wide roll out.

The survey conducted with the 11 knowledge-management champions indicated that 9 respondents recognise knowledge management as a business tool and therefore acknowledge the significant contribution that knowledge management can make. Eight respondents were of the opinion that CoPs benefit the business and elaborated that CoPs added value to business processes and facilitated a culture of transparency. Eight respondents had one to two years of experience with CoPs, given the reality that CoPs only gained attention three years prior to the commencement of the research project. Considering that only two of the 11 knowledge champions that were interviewed did not recognise the importance of the contribution that CoPs and knowledge management made within the organisation begs the question whether these two knowledge champions adhered to the criteria that were used to select knowledge champions. When asking whether CoPs were established and managed more regularly on a face to face or a virtual basis, the results showed that the existing CoPs interact on a face to face level more regularly than a virtual level.

On an organisational level, the role of CoPs in MultiChoice is largely seen in a positive, and the perception exist that it is beneficial to the business processes. It is in the organisation's best interest to continuously monitor the attitudes and perceptions of employees regarding the use of CoPs to establish whether these continue to serve their purpose in knowledge sharing and the management of the organisation's intellectual assets.

Sandrock (2008:79) suggest that the following activities are conducted within a CoP to assist in building a learning organisation:

- Assisting with knowledge mapping: This is defined as networking and building on knowledge expertise within the organisation and accumulating this information in a database for future reference. The knowledge database for CoPs are not extensively utilised as the survey results indicates that $60 \%$ of the participants do not believe that there is a divisional platform to share information in MultiChoice. The development of the collaboration platform, which is a result of the PAR group interaction, will be able to accomplish the CoPs goal of becoming learning organisations via knowledge mapping.

- Process mapping: Each division has a fundamental process that should be mapped in a CoP. It is clear from the PAR focus groups that members do believe that CoPs assist with validating and improving business processes. However the extent to which this is done has not been made explicit and further investigation is required.

- Determining best practices: What serves as a good practice in one business unit could potentially lead to a best practice for the rest of the organisation to implement. It is clear from the PAR focus groups held that the members do believe that best practices can materialise from CoPs. One such best practice is the development of the collaboration framework as suggested in the planning phase of the experiential learning cycle for the knowledge management CoPs.

- Captured shared learning: CoPs are good places to share experiences and lessons learnt. Results from the survey's responses to the question whether respondents view CoPs as adding value to the business indicated that, through lessons learnt, shared experiences and how work is done, there is a perception that CoPs are of value. Furthermore during the PAR group sessions, the project-management $\mathrm{CoP}$ indicated that the platform for project managers to collaborate serves as an effective tool to share lessons learnt. The knowledge-management $\mathrm{CoP}$, had similar feedback to the effectiveness of collaboration platforms to capture lessons learnt.

The results of the 2006 baseline report indicated that MultiChoice implemented CoPs to overcome some of the perceived challenges. Challenges included employees expressing the need to share knowledge and experience, but they were of the opinion that they did not have the time to do that. Further challenges showed that information and knowledge need to be shared and communicated in a closer, innovative, collaborative environment, across departmental silos, and internal communication needs attention with the requirement for more innovative means of communication.

The results of the survey signified that CoPs are seen as valuable to the business. The transparency which is created

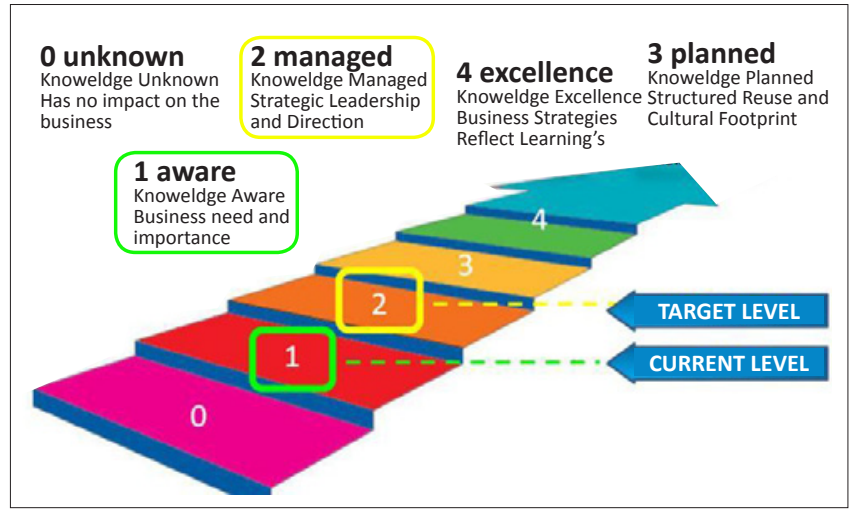

Source: Authors' own data

FIGURE 7: Maturity level of MultiChoice. 
by CoPs lead to more learning across the organisation since business units work together rather than in silos. The problem of the retention of intellectual property and the overall threat of losing skills and knowledge to competitors and the market, both permanent and contract-based employees, are recognised. The results from the survey and focus group discussions indicated that MultiChoice has progressed one level on the knowledge-management maturity model and has entered level two (Figure 7).

This means that MultiChoice has grown from a level of being unaware, during the 2006 baseline study, to a level of having limited awareness of knowledge management. A level of awareness has been created, and the significance of knowledge management as a vital business tool has recently been realised. The next level of achievement for MultiChoice is to reach the 'knowledge managed' level as indicated in Figure 7. The typical activities in a learning organisation have become more prevalent in MultiChoice since the initial baseline study. The environment that has been created through CoPs to solve problems systematically and the experimentation with new approaches is another step for MultiChoice towards becoming a learning organisation.

An organisation needs to mature its knowledge capabilities and measure its knowledge assets if it is interested in determining its intellectual capital (Ngosi, Helfert \& Braganza 2011:302). Kruger and Johnson (2011:270) see knowledgemanagement maturity not only in terms of growing capability, but they focus on the richness and consistency of execution in reaching an idealistic ultimate state of processes being defined, managed, measured and controlled.

\section{Recommendations and conclusion}

As would be expected, knowledge-management implementation at MultiChoice has been a relatively slow process, yet the next level in the knowledge management maturity model, namely knowledge managed through strategic leadership and direction, is within reach. The existence of CoPs played a significant role in stimulating the awareness that knowledge management plays a vital role in the business, bringing the organisation one step closer to becoming a true learning organisation. The use of participatory action research as a relevant methodology for knowledge-management research was also proven through CoPs acting as action learning groups in themselves that learn from experience and actions through the experiential learning cycle. In fact, the experiential learning cycle was adopted as a collaboration framework to encourage the online sharing of expertise and innovation. It is evident from the results that CoPs in MultiChoice have a significant role to play and will become increasingly valuable.

CoPs offer both virtual and face-to-face platforms where sharing and consequently learning takes place so that the bridge between working and innovation can be created. CoPs form powerful and collective knowledge-sharing opportunities, and the knowledge can be effectively managed, especially in a virtual environment. Thus, empowering people to learn can act as an impetus generating the drive towards becoming a learning organisation. CoPs are instrumental in creating, acquiring and transferring knowledge and in modifying the organisation's behaviour to reflect new knowledge and insight, thereby expanding its capacity to create its own future. The steps that are required to become a learning organisation are embedded in the very nature of CoPs in, firstly, being a platform that creates an environment that is conducive to learning. Secondly, the exchange of ideas is stimulated, seeing that it is the actual reason why CoPs are formed. Thirdly, with the sharing of ideas in CoPs, they become learning forums where new knowledge leads to innovation.

Lessons learnt from this research at MultiChoice include some findings that can be generalised. CoPs should be in a mature phase of the knowledge-management maturity model to be in a position to be measured fiscally. Fiscal proof indicating the monetary value of the IC encapsulated within the CoP exchanges of any organisation can only be established when the CoPs have progressed through a specific time frame. Three time frames within knowledge management have become apparent from this research. The first time frame is dependant on quantity in a process to get as much input from CoPs as possible. The second time frame is typified by quality, when the company is sifting through the numerous inputs gathered during the quantity phase so that valuable, reusable contributions can be extracted. The third time frame represents measurements, the process that takes the quality extracted from the quantity and measures the return on investment, therefore measuring reusable inputs. This remains a process that happens over time, and organisations need to assess their status within these time frames to establish their next step. The final finding that can be generalised from this research is that PAR as a researchdesign approach has been shown as a very valuable technique in the field of knowledge-management research.

The results of this research point toward the significant role that CoPs play in creating a learning organisation. However, the actual impact, especially how to establish the extent of value-added by CoPs, require further fiscal investigation to determine a monetary value. Fiscal value will be established when direct IC can be measured. In the words of Winston Churchill: 'However beautiful the strategy one must occasionally look at the results.' The monetary value of knowledge as an asset needs to be ascertained.

\section{Acknowledgements Competing interests}

The authors declare that they have no financial or personal relationship(s) which may have inappropriately influenced them in writing this paper.

\section{Authors' contributions}

L.C. (University of Johannesburg) conducted the research as a postgraduate student under the supervision of 
M.M. (University of Johannesburg). L.C. (University of Johannesburg) and M.M. (University of Johannesburg) jointly developed all data collection instruments.

L.C. (University of Johannesburg) collected the data and the work was written up as a research report by L.C. (University of Johannesburg).

The review of the report from which this article was extracted as well as the writing of the article was done by M.M. (University of Johannesburg) and L.C. (University of Johannesburg) reviewed and commented where necessary.

\section{References}

Aktharsha, U.S. \& Anisa, H., 2011, 'Knowledge management systems and learning organisation: an empirical study in an engineering organisation', The IUP journal of knowledge management IX(2), 26-43.

Arling, P.A. \& Chun, M.W.S., 2011, 'Facilitating new knowledge creation and obtaining KM maturity', Journal of knowledge management, 15(2), 231-250. http://dx.doi. org/10.1108/13673271111119673

Barab, S.A. \& Duffy T., 1998, 'From practice fields to communities of practice', Centre for Research on Learning and Technology, Indiana University, Indiana.

Bontis, N., 1998, 'Intellectual capital: An explanatory study that develops measures and models', Management Decision 36(2), 63-76 http://dx.doi. org/10.1108/00251749810204142

Burke, M., 2000, 'Communities of practice', Public roads 63(6), 18-21.

Carrillo, P., 2004, 'Managing knowledge: Lessons from the oil and gas sector', Construction Management and Economics 22, 631-642. http://dx.doi. Construction Management and
$\mathrm{org} / 10.1080 / 0144619042000226289$

Currie, G. \& Kerrin, M., 2004, 'The limits of a technological fix to knowledge management', Management Learning 35(1), 9-29. http://dx.doi. org/10.1177/1350507604042281

Davel, R. \& Snyman, M.M.M., 2005, 'Influence of Corporate Culture on the use of knowledge management techniques and technologies', South African Journa of Information Management (7)2, viewed 17 February 2011, from http://www. sajim.co.za

Earl, M., 2001, 'Knowledge management strategies: Toward a taxonomy', Journal of Management Information Systems 18(1), 215-233.

Edvinson, L., 2002, Corporate longitude, Prentice Hall, London.

Gallagher, S. \& Hazlett, S.A., 2000, 'Using the Knowledge Management Maturity Model (KM3) as an evaluation tool', Proceedings of the Conference on Knowledge Management Concepts and Controversies, Coventry, UK, 10-11 February 2000.

Garvin, D.A., 1993, 'Building a learning organisation', Harvard Business Review on Knowledge Management 71(4), 78-91.

Gilley, J.W. \& Maycunich, A., 2000, Beyond the learning organisation, Perseus books, Cambridge.

Genat, B., 2009, 'Building emergent situated knowledges in participatory action research', Action Research 7(1), 101-115. http://dx.doi org/10.1177/1476750308099600

Gurteen, D., 2010, Gurteen Knowledge Website, viewed 17 February 2011, from http://www.gurteen.com

Hiscock, M., 2006, 'Knowledge management baseline assessment', Unpublished internal report for Multichoice.

Hwang, Y., 2005, 'Investing enterprise systems adoption: Uncertainty avoidance, intrinsic motivation, and the technology acceptance model', European Journal of Information Systems 14, 150-161. http://dx.doi.org/10.1057/palgrave. ejis.3000532
Hughes, I. \& Seymour-Rolls, K., 2000, 'Participatory action research: Getting the job done', Action Research eReports 4 , viewed 17 February 2011, from http://www. done, Action Research eReports 4, view
fhs.usyd.edu.au/arrow/arer/004.htm

Industry Canada, 1999, 'Measuring and reporting intellectual capital', viewed 17 February 2011, from http://www.strategis.ic.gc/SSG/pi00009e.htm

Jeon, S., Kim, Y. \& Koh, J., 2011, 'Individual, social, and organisational contexts for active sharing in communities of practice', Expert Systems with Applications 38 12423-12431, http://dx.doi.org/10.1016/j.eswa.2011.04.023

Klein, D.A. (ed.), 1998, The strategic management of intellectual capital. ButterworthHeinemann, Boston.

Klimko, G., 2001, 'Knowledge management and maturity models: Building common understanding', Proceeding of the 2nd European Conference on Knowledge Management, IEDC Bled School of Management, Bled, Slovenia, 08-09 November 2001.

Kohn, A., 1999, Punished by rewards: The trouble with gold stars, incentive plans, A's, praise and other bribes, Houghton Mifflin, New York.

Kolb, D.A., \& Yeganeh, B., 2011, 'Deliberate experiential learning: Mastering the art from learning from experience', ORBH Working paper case, Western Reserve University, viewed 24 April 2012, from http://learningfromexperience.com/ research-library/deliberate-experiential-learning/

Kruger, C.J. \& Johnson, R.D., 2011, 'Is there a correlation between knowledge management maturity and organisational performance?', The Journal of Information and Knowledge Management Systems 41(3), 265-295.

MultiChoice, 2010, About MultiChoice, viewed 17 February 2011, from http://www. multichoice.co.za

Murphy, S., 2008, 'Critical success factors for communities of practice at MultiChoice', Masters dissertation, Gordon Institute of Business Science, University of Pretoria, South Africa.

Ngosi, T., Helfert, M. \& Braganza, A., 2011, 'Increasing knowledge management maturity in organisations: A capabilities-driven model', Proceedings of the 3rd European Conference on Intellectual Capital, University of Nicosia, Cyprus, 18-19 April 2011

Nickols, F., 2003, Communities of practice: A start-up kit, viewed 17 February, from http://www.nickols.us/CoPRoles.pdf

Pearlson, K. \& Saunders, C., 2006, Managing and using information systems, John Wiley \& Sons, New Jersey

Pink, D.H., 2010, Drive: The surprising truth about what motivates us, Canongate, Edinburgh.

Sandrock, J., 2008, The art of managing knowledge, Corpnet, Johannesburg.

Senge, P., 1990, The fifth discipline: The art and practice of the learning organisation, Doubleday, New York.

Smith, P.A.C., 2011, 'Elements of organisational sustainability', The Learning Organisation 18(1), 5-9. http://dx.doi.org/10.1108/09696471111095957

Snyman, M.M.M. \& Kruger, C.J., 2005, 'Formulation of a Strategic Knowledge Management Maturity Model', Journal of Knowledge Management 8(1), 5-10 http://dx.doi.org/10.1108/13673270410523871

Stafford, C. \& Mearns, M., 2009, 'What happens when organisations embrace social networking? Knowledge sharing at a multinational business solutions corporation', South African Journal of Information Management 11(4), viewed 14 June 2010, from http://www.sajim.co.za

Stevenson, D., 1995, Intellectual Capital and EA, viewed 14 June 2010, from http:// www.users.iafrica.com

Sullivan, P., 2000, Profiting from intellectual capital: Extracting value from innovation, Wiley, New York.

Sveiby, K.E., 1997, The new organisational wealth, Berett-koehler, San Francisco.

Wenger, E., 2007, Communities of practise leaning as a social system, viewed 14 June 2010, from http://www.co.i.l.com/coil/knowledge-garden/cop/lss.shtml

Wilson, P.N., 2011, 'Shared learning in and from transformational development programs', Transformation: An International Journal of Holistic Mission Studies, 28(2), 103-113.

Zhou, A.Z. \& Fink, D., 2003, 'The intellectual capital web: A systematic linking of intellectual capital and knowledge management', Journal of Intellectual Capital 4(1), 34-38. http://dx.doi.org/10.1108/14691930310455379 